\title{
INNOVATION MINDSET MODEL AT THE EARLY STAGE STARTUP WITH BERKELEY INNOVATION INDEX APPROACHED
}

\author{
Sarika Fitri ${ }^{1}$ \\ Faculty of Computer Sciences, \\ STIMIK ESQ, Indonesia \\ (Email: sarikafitriayi@gmail.com) \\ Asri Pertiwi \\ Faculty of Computer Science, \\ STIMIK ESQ, Indonesia \\ (Email: asri.pertiwi@esqbs.ac.id)
}

Accepted date: 05-03-2019

Published date: 09-07-2019

To cite this document: Fitri, S., \& Pertiwi, A. (2019). Innovation Mindset Model at The Early Stage Startup with Berkeley Innovation Index Approach. Journal of Information System and Technology Management, 4(13), 57-70.

DOI: $10.35631 / J I S T M .413006$

\begin{abstract}
Digital startups play an important role in the growth of nation's economy, but many startups fail within their first year due to lack of any new ideas. This paper concentrates to modelling innovation mindset of founder to answer how can innovation mindset of founders be able to influence the propensity to innovate and what factors of which innovation mindset at need to be possed by the founders to encourage personal innovation. In this research, the presenting data and the method used is descriptive qualitative. The unit analysis of this study were startups digital with minimum running at validation phase, early stage and bootstrapping criteria and the informants were Top Management Team (TMT) level known as founder or cofounder who convey optimism and consistently manage the resources for innovation that will lead to successful innovation. Data were collected by triangulation technique which is Berkeley Innovation Index (BII) questionnaire to measure innovation mindset index with 6 constructsTrust; Believe; Resilience; Perfection; Diversity; Collaboration. Then, conduct a quick response statement, and the last is interview based on BII constructs. The result of this research produced the personality traits model, this model overview of how to get higher propensity to innovate at the early stage digital startup. As a conclusion from the model it delivered 4 propositions about the propensity to innovate by individuals.
\end{abstract}

Keywords: Innovation Mindset, Early Stage, Digital Startup, TMT, BII

\section{Introduction}

Todays, the startups with their digital innovation have been vital to a country's economic activity level in term of the expansion and creation of jobs, helping the civilian labor force. Moreover, it also improves a nation's technological advancements for future development and growth of the economy. Researchers admitted that digital innovation does play an important 
role in the growth of nation's economy (McGuirk, Lenihan, \& Hart, 2014; Amore, 2015; Giardino, Wang, \& Abrahamsson, 2014). On a global scale, Indonesia has been ranked fourth for possessing a rather large number of startups, totalling up to 1,559 (startupranking, 2018). A startup is defined as successful once it reaches the "Unicorn" stage, when it becomes valued at over $\$ 1$ billion USD. In the context of Indonesia, it can be said that local startups successfully attract the attention of global investors. As seen from the Crunch-base data in 2018, it mentioned that Indonesia already has four startups with the status of "Unicorn".

Although unicorn startups in Indonesia are on the rise, the development of new startups have declined over the past years. From TechinAsia, a media that monitors the development of startups, indicated how the numbers of established startups have been generally decreasing over the last few years. To start and close a business is an ongoing process, and the startup failure rate can also reach $90 \%$ (Koster \& Hans, 2017). In other words, the possibility of failure is more certain than the possibility of success, and then there have been various ways to minimize the possibility of such failure. Stages of programs such as incubators, accelerators, co-working space and government initiatives have actually been done in order for startup actors to flourish. However, it does not seem to have proven results with the number of startups that also automatically lower funding a startup. Though it is known that many agencies both local and global that provides funding assistance at startup. According to the insight of $42 \%$ global startup failure is a product that is needed by the market (CBInsights, 2017). In line with what was presented by Alyssa Maharani from Digita Raya, many startup failures are in the product market fit (Putri, 2018). Then, it is very unfortunate that this happens mostly at startups that have just started pioneering.

Things that need to be owned and developed for the sustainability of any company including startup is innovation. It needs to be seen as the most important variable to create competitive advantage so as to promote economic growth (Sidhu, et al, 2016). Whether or not a company puts innovation above other priority interests, without the right innovation metrics, the company would not improve. At the same time, they have a large number of metrics to measure things from profitability, inventory turnover, payback and more but not to measure innovation. Innovation, as a competitive economic factor, is a process that requires continuous management, development and control (Solomon, 2016). Therefore, an innovative company needs to measure its innovative ability to be in good company state. In the midst of a world that encourages continuous progress without the ability to innovative an organization or individual will suffer huge losses (Sidhu, et al., 2016). Innovation is synonymous with introducing novelty (Amar \& Mullaney, 2017), and this relates to creativity to generate useful ideas (Sarooghi, Libaers, \& Burkemper, 2015). Innovative is positively related to the performance of startup companies (Hyytinen, Pajarinen, \& Rouvinen, 2015). This startups are required to focus on creating innovative products or services (Giardino, Wang, \& Abrahamsson, 2014) and introduce novelty with limited resources. To reach continuously innovation, the ability to innovate of individuals is believed will add the value of startups. Individuals also become frontline guards who move organizations to learn from external sources and then contribute to the company's innovation strategy.

Therefore, the successful of early stage startup is very dependent on the role of the founder and co-founder who are in the Top Management Team (TMT), because the trustable TMT level can convey optimism and consistently manage the resources for innovation that will lead to successful innovation (Kuczmarski, 2003). 
Based on the above exposure, this paper addresses these following questions as a problem statement, (1). How can the innovation mindset of an Individual TMT level at the early stage digital startup be able to influence the propensity to innovate personally?. This question generates the second question, (2) What factors of which innovation mindset at need to be possed by the TMT level individual to encourage personal innovation? We measure the innovation mindset based on Berkeley Innovation Index then continued with interview to get more in-depth results. This research focus on a selected startup at early stage with two objectives. First, to get innovation mindset of TMT level model that can drive personal innovation with the benchmark of Berkeley Innovation Index. Second, to know the important factors at TMT level needs to be capable of encouraging personal propensity to innovate.

\section{Theoretical Framework}

\section{Innovation}

Innovation is believed to be one of the main drivers of company's productivity and growth (McGuirk, Lenihan, \& Hart, 2014) and becoming one of its main strategic goals. The importance of the emergences of innovation for economic growth has been documented in some researches and become the part of the growth theory. Starting from Joseph A Schumperter known as an economist, first to emphasize the importance of a new product as an internal stimulus economic growth. Innovation can be explained as a pervasive attitude, a feeling, an emotional state, an ongoing commitment to novelty. It is a set of values that represent trust to look beyond the present and make that vision a reality (Kuczmarski, 2003). As explained above that not all entrepreneurial mindset benefits for entrepreneur activity (Mathisen \& Arnulf, 2013), because it influenced by several factors, especially environmental factors (Sarooghi, Libaers, \& Burkemper, 2015). 


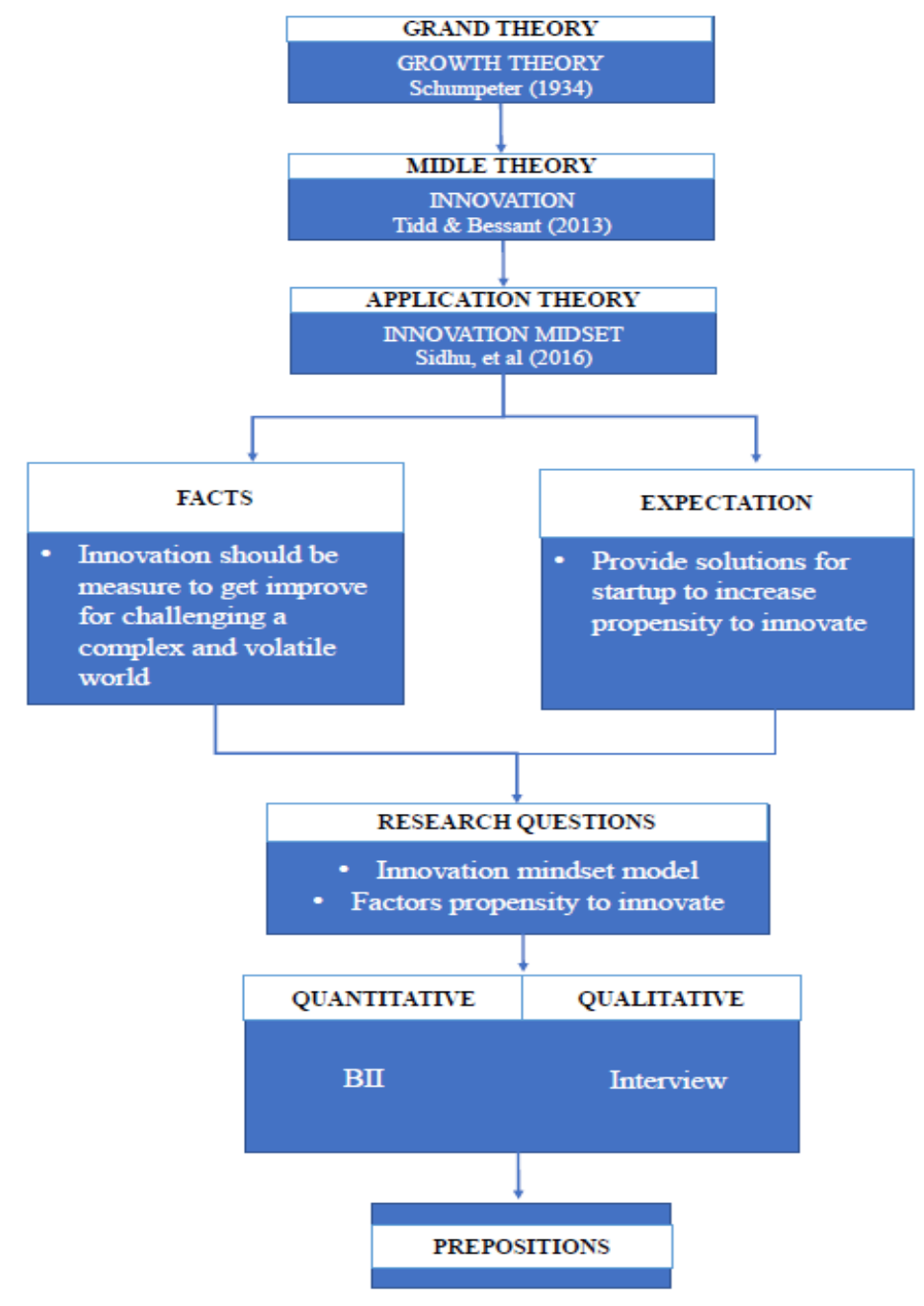

Figure 1: Theoretical Framework

The right environment for an entrepreneur will encourage creativity, where creativity is part of the innovation process (Hormiga, Hancock, \& Valls-Pascola, 2013). Propensity to make innovation is a mindset is belief in one's ability to innovate must be steadfast, consistent, and deep. Because innovation is a mindset rather than a series of sequential activities. It requires an attitude of positive self-esteem. It supports a buoyant and optimistic belief that, over time, innovation will result (Kuczmarski, 1996).

Entrepreneurship has a positive effect on innovation (Hacioglu, 2012) \& (Ma'toofi \& Tajeddini, 2010). Enterpreneur's desire to take a risks, tolerate risk and uncertainty is a prominent feature of understanding that getting innovation is closely related to startups endurance during the development phase (Hyytinen, Pajarinen, \& Rouvinen, 2015). For that, specific personal factors are essential to the pursuit of entrepreneurship especially during the crisis period (Bullough \& Renko, 2013). This personal factor is closely related to the mindset. The activities of entrepreneurs can contribute to the implementation of innovative ideas (Lee \& Hsieh, 2010). Open innovation drives the need to improve the entrepreneur mindset (Mantas \& Soderquist, 2010) and relevance is highly in line with the business model at Startup (Fontana, 2011). 


\section{Innovation Mindset}

The mindset is associated with the entrepreneur in constructing a problem and devising a solution (Mathisen \& Arnulf, 2013). According to George Courus innovator's mindset is "belief that abilities, intelligence, and talents are developed so that they lead to the creation of new and better ideas (Courus, 2015). Propsensity to make innovation is a mindset, it is belief in one's ability to innovate must be steadfast, consistent, and deep. This is what distinguishes between entrepreneurs and businessmen and workers. Entrepreneurs build ideas from emerging empathy to tackle social and community issues. For that entrepreneur tend to prefer the impact that occurs from the solution is compiled rather than profit alone (Morato, 2012). Entrepreneurs are positioned differently on an individual level, company level and macro level. By the time it reaches the macro level it will have an impact on economic growth (Sidhu, et al., 2016a). The propensity to innovate is a characteristic that builds company performance both at the individual and organizational level (Sidhu, et al., 2016). The propensity to innovate at an individual level enables an entrepreneurial spirit to materialize ideas that add value to the company. But the propensity to innovate is dependent on the level of creativity of the entrepreneur (Pereira-Leite \& Morales, 2015) and evidently fused into the organization (Santos, et al., 2017).

The Berkeley Innovation Index (BII) is an approach based on the Berkeley Method of Entrepreneurship (BMoE) project designed with the initial goal of being a holistic teaching and learning approach that enables individuals to engage and learn entrepreneurship. BII includes three main elements; infrastructure, mindset, and tactics (Sidhu, et al., 2016) developed to measure innovation rates based on psychological history and perceptions on organizational culture. The step to identify the psychological constructs of entrepreneurial mindset and innovation is based on the work that exists on known variables through six sub-traits personality traits that affect a person's mindset to innovate (Larsson \& Ojala, 2016).

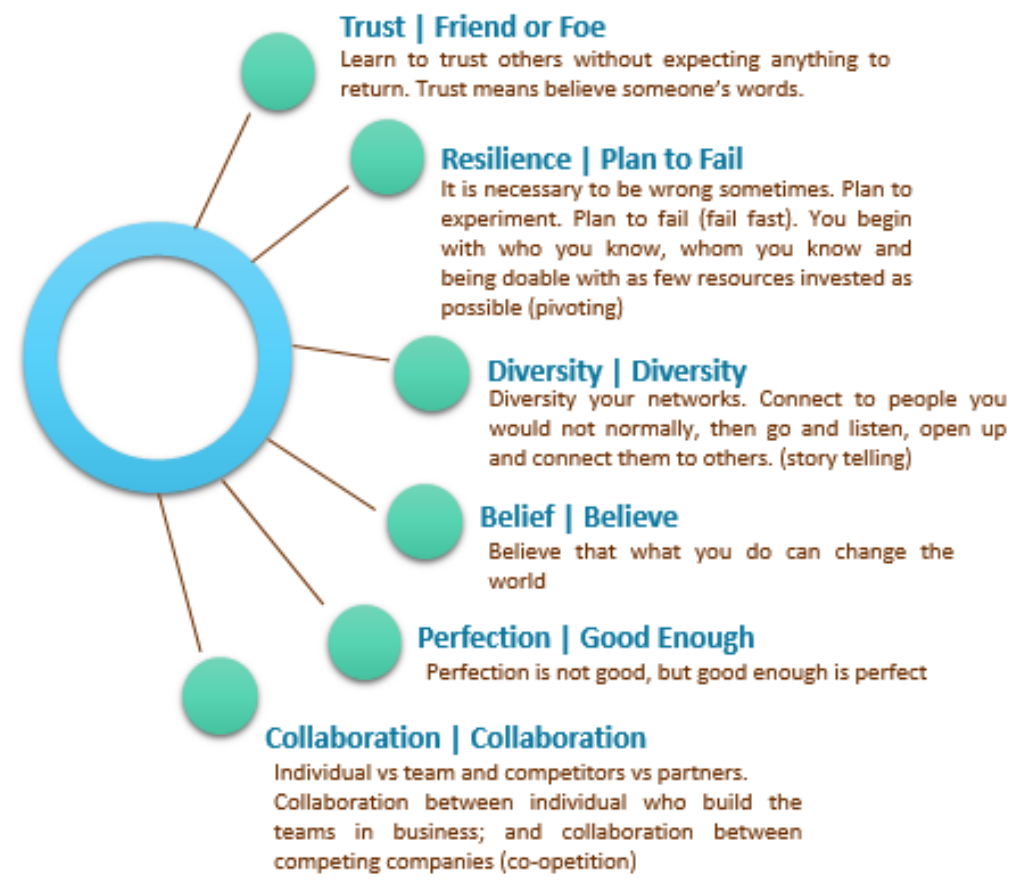

Figure 2: Personality Traits and Mindset According to BII 


\section{Top Management Team}

Top Management Team (TMT) Level is the top-ranking executive within an organization, which is responsible for the performance of the entire company. Including chairman, CEO, managing director, president, executive director, vice president, etc. The main job of the TMT level is to formulate goals, objectives, and strategies. For example, by how relevant business modes to build (wikipedia). TMT has an influence on the orientation of corporate strategic innovation with particular relevance in deciding the overall strategic direction of the company, the composition of the project portfolio, and the allocation of resources across innovation projects (Talke, Salomo, \& Kock, 2011). Therefor it can be said that TMT level plays an important role in the innovation of company. Startup company has three important actors. They are hustler, hipster and hacker, known as founder, co-founder or ceo, it can be said as TMT.

\section{Research Method}

\section{Research Design}

The research was designed using single case study. This design is chosen to know how and why in knowing innovation mindset model in TMT Level on Start-up in validation phase. The type of approach taken in this study using descriptive qualitative with analytical methods. This approach is chosen because in qualitative research to examine the problems or events that are underway in the present conditions, the researcher did not prove anything or decline the hypothesis that has been made before, but the researchers process the data and analyze a problem in non-numeric form (Sugiyono, 2017). With these understanding, then this type of research focuses on the description of data in the form of sentences that have deep meaning derived from the informant. In this study using a qualitative approach to find the model and describe the innovation mindset that existed at startup which is still in the phase of validation.

Table 1. Variable of Innovation Mindset

\begin{tabular}{|l|l|}
\hline \multicolumn{1}{|c|}{ Variable } & \multicolumn{1}{c|}{ Statement } \\
\hline Trust & $\begin{array}{l}\text { Most people can be trusted. } \\
\text { Most people tell a lie when they can benefit by doing so. } \\
\text { I trust other people. } \\
\text { Those devoted to unselfish causes are often exploited by others. } \\
\text { How long does it typically take you to generate a basic level of trust from a } \\
\text { person you just met? }\end{array}$ \\
\hline Resilience & $\begin{array}{l}\text { I can accept failures as part of a learning process } \\
\text { Failures often lead to positive outcomes in the long run } \\
\text { I quickly overcome setbacks } \\
\text { Failures allow opportunities for reflection and consideration }\end{array}$ \\
\hline Diversity & $\begin{array}{l}\text { It is important to me to interact with people that are different from me. } \\
\text { Ifrequently come in contact with people that are different from me. } \\
\text { Ifeel comfortable to talk to people that are different from me. } \\
\text { Interacting with other persons makes me interested in things that happen } \\
\text { outside of my field. }\end{array}$ \\
\hline Believe & $\begin{array}{l}\text { I can succeed at any endeavor to which I set myself. } \\
\text { I have been able to successfully overcome many challenges. }\end{array}$ \\
\hline
\end{tabular}




\begin{tabular}{|l|l|}
\hline Perfectionist & $\begin{array}{l}\text { When facing difficult tasks, I am certain I will accomplish them. } \\
\text { I have been able to achieve most of the goals I set for myself. } \\
\text { When I see a better way to do something, I can influence the "organization } \\
\text { where I work" or the "people around me "to adopt that new approach. } \\
\text { I would prefer to hand in a product on time rather than making it perfect. } \\
\text { In general, quality and perfection are more important than effectiveness. } \\
\text { I would rather create something that is cost effective than the highest } \\
\text { possible quality. }\end{array}$ \\
\hline Collaboration & $\begin{array}{l}\text { There are times when it makes sense to collaborate with my competitors. } \\
\text { An active cooperation with my collaborators is important to me. } \\
\text { A cooperation with one of my enemies could be very important to my firm. } \\
\text { There are times when I would be open to share resources and information } \\
\text { with my competitor. }\end{array}$ \\
\hline
\end{tabular}

Source: Sidhu et.al, 2016

Our research objective was to find out the innovation mindset model and the factors that influenced at the early stage startups. Interviews were conducted on TMT level from selected startups. Instrument of interview was developed from six variables of Barkeley Innovation Index reference. The informant was selected through 37 startups who had already filled the questionnaire. The criteria of startup to be an informant are bootstrap startups which are in the position of early-stage in Jakarta and have passed at least validation phase. It means, startups are recognized by users through any social media and having daily transactions. They are the CEO or founder from Tanijoy, Shipper, Skleem and Sarang Jasa.

\section{Data Analysis and Result}

This research used inductive descriptive analysis technique to analyse data from samples by describing data that has been collected as it is with the intention of making conclusions that apply to the population. The data obtained will be described or illustrated as is with aim of drawing a conclusion that apply to public. Research instrument obtained through the three steps. They are observation, distributed questionnaire and interview. Observation activities were conducted to observe the behaviour of digital startup in the incubator ecosystem and capturing the characteristics of startup under different incubators. Questionnaire was distributed based on the Innovation Mindset framework, consisting six main variables as described above. Then, the result of the questionnaire is calculated by the formula of BII Index and get the result of innovation mindset level with range 1 to 10. This result then mapped in the spider graph. Each graph is grouped according to startup type based on startup development phase i.e. formation, validation and growth. We did interview to the selected startups who have reached the validation phase, namely Tanijoy, Shipper, Sarang Jasa and Skleem. Structured is chosen because the interviewer has known for sure about the information to be obtained through the six predefined variables and each informant has the same question. The types of questions asked use both closes question and open questions. This study use three kind of data analysis. They are descriptive analysis, radar graph analysis and domain analysis. 


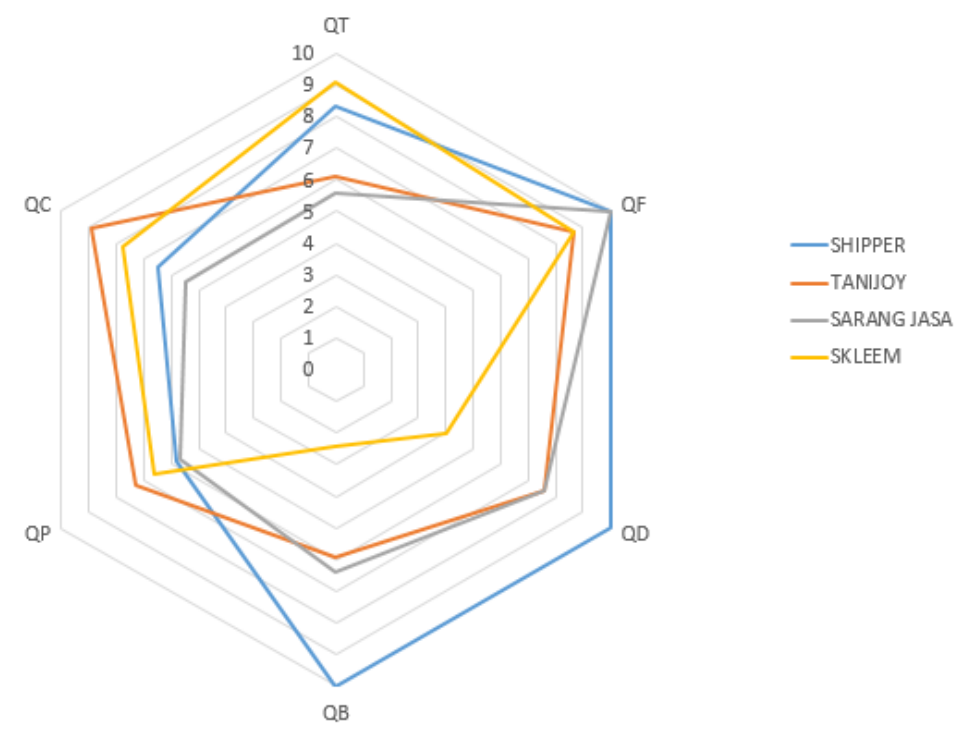

Figure 3: Spider Graph of Informant's Innovation Mindset Index

From the measurement of innovation mindset with BII, it is found that innovation mindset index of Sarang Jasa is 5.7, Skleem is 6.5, Tanijoy is 7.4 and Shipper is 8.4. From the above picture, Shipper has the highest value of 10 for the plan to fail (QF), diversity (QD) and belief (QB) variables, while the lowest index for collaboration (QC) and trust (QT) occurs in the Sarang Jasa, and the highest of perfection variable (QP) is Tanijoy. The result of BII was used as a reference for conducting interviews that divided into two stages, quick response statement with yes and no answer only and in depth interview as a confirmation of the quick response statement. We did reduction from two type of interview and then proceed with comparing variable analysis between trust and collaboration and belief and resilience. Variable of diversity and perfection was analysed as individual variable.

Table 2. Comparing Analysis for Trust and Collaboration

\begin{tabular}{|c|c|c|c|c|}
\hline Startup & $\begin{array}{c}\text { Index } \\
\text { QT }\end{array}$ & $\begin{array}{c}\text { Index } \\
\text { QC }\end{array}$ & $\begin{array}{c}\text { Trust in } \\
\text { Co-Founder }\end{array}$ & $\begin{array}{l}\text { Trust in } \\
\text { Competitor }\end{array}$ \\
\hline Sarang Jasa & 5.6 & 5.5 & $\begin{array}{l}\text { Must to be unknown } \\
\text { with the same vision }\end{array}$ & $\begin{array}{l}\text { Sharing information } \\
\text { done if Mutual values } \\
\text { assets. } \\
\text { Collaboration only } \\
\text { with competitors with } \\
\text { same vision because } \\
\text { of wide impact }\end{array}$ \\
\hline Tanijoy & 6.1 & 8.9 & $\begin{array}{l}\text { Trust is built together } \\
\text { from first impression }\end{array}$ & $\begin{array}{l}\text { Done if Mutual values } \\
\text { assets } \\
\text { Collaboration } \\
\text { startup in the same } \\
\text { area, } \\
\text { products }\end{array}$ \\
\hline
\end{tabular}




\begin{tabular}{|c|c|c|c|c|}
\hline Shipper & 8.3 & 6.5 & $\begin{array}{l}\text { Trust is built together } \\
\text { from basic } \\
\text { assumption (zero). } \\
\text { Vision, experience, } \\
\text { capability, and value } \\
\text { are known over time } \\
\text { after joining }\end{array}$ & $\begin{array}{l}\text { Sharing information is } \\
\text { freely open } \\
\text { Only collaboration } \\
\text { with competitors with } \\
\text { the same vision } \\
\text { because of wide } \\
\text { impact }\end{array}$ \\
\hline Skleem & 9.1 & 7.8 & $\begin{array}{l}\text { Using levels: } \\
\text { 1. First Impression } \\
\text { 2. Reference } \\
\text { 3. Experience } \\
\text { 4. Ability } \\
\text { 5. Testing }\end{array}$ & $\begin{array}{l}\text { Sharing information is } \\
\text { semi-open, only } \\
\text { general information is } \\
\text { shared } \\
\text { Collaboration with } \\
\text { startup on the same } \\
\text { area, } \\
\text { expertise }\end{array}$ \\
\hline
\end{tabular}

The result above indicates that mostly startup do sharing knowledge openly and collaborate with the same area of startup to their effort in innovating. Experiment activity is one of the part to explore new knowledge for startup to be innovate but need to balance with exploitation activity. It can be shown from the analysis below.

Table 3. Analysis for Perfection

\begin{tabular}{|c|c|l|}
\hline Startup & $\begin{array}{c}\text { Index } \\
\text { QP }\end{array}$ & \multicolumn{1}{c|}{ Perfectionist } \\
\hline Sarang Jasa & 5.7 & $\begin{array}{l}\text { No team. } \\
\text { He recommended that exploration and exploitation be } \\
\text { done by two different Co-founders } \\
\text { Perceived Personal Ambidexterity }\end{array}$ \\
\hline Shipper & 5.8 & $\begin{array}{l}\text { Explorations through experiments need to be done as } \\
\text { replacement of R\&D division } \\
\text { Lack of resources } \\
\text { Perceived Personal Ambidex }\end{array}$ \\
\hline Skleem & 6.6 & $\begin{array}{l}\text { Exploration is important but do not overdo it. There is } \\
\text { time for implementation } \\
\text { Contextual ambidexterity }\end{array}$ \\
\hline TaniJoy & 7.3 & $\begin{array}{l}\text { Exploration and exploitation based on relevant division } \\
\text { Structural ambidexterity }\end{array}$ \\
\hline
\end{tabular}

Table 4. Comparing Analysis for Belief and Resilience Variable

\begin{tabular}{|c|c|c|c|c|}
\hline Startup & $\begin{array}{c}\text { Index } \\
\text { QB }\end{array}$ & $\begin{array}{c}\text { Index } \\
\text { QF }\end{array}$ & $\begin{array}{l}\text { Believe to change the } \\
\text { world }\end{array}$ & Willing to change \\
\hline Sk & 2.4 & 8.7 & $\begin{array}{l}\text { There is no doubt } \\
\text { because of the type of } \\
\text { commerce transaction } \\
\text { B2B. (Small impact) } \\
\text { Mental Strength: give } \\
\text { in, not confidence }\end{array}$ & $\begin{array}{l}\text { Mistakes come by } \\
\text { itself } \\
\text { Failure is learned to } \\
\text { find a solution } \\
\text { High Risk: Initiate a } \\
\text { startup }\end{array}$ \\
\hline
\end{tabular}




\begin{tabular}{|c|c|c|c|c|}
\hline TaniJoy & 5.9 & 8.7 & $\begin{array}{l}\text { Doubts arise because if } \\
\text { negative thoughts in } \\
\text { changing the system } \\
\text { and future } \\
\text { Mental Strength: Self } \\
\text { Confidence }\end{array}$ & $\begin{array}{l}\text { Mistakes come by } \\
\text { itself } \\
\text { Don't make a same } \\
\text { mistake for second } \\
\text { time } \\
\text { High Risk: Initiate a } \\
\text { startup }\end{array}$ \\
\hline Sarang jasa & 6.4 & 10 & $\begin{array}{l}\text { Doubt is natural, but } \\
\text { still have to be } \\
\text { confident } \\
\text { Mental Strength: Self- } \\
\text { Assurance }\end{array}$ & $\begin{array}{l}\text { Must having mistakes } \\
\text { Fixed as much as } \\
\text { possible } \\
\text { High Risk: Team }\end{array}$ \\
\hline Shipper & 10 & 10 & $\begin{array}{l}\text { There is no doubt } \\
\text { because of great } \\
\text { purpose }\end{array}$ & $\begin{array}{l}\text { Must having mistakes } \\
\text { Seeking solutions } \\
\text { before failures arrives } \\
\text { High Risk: Process }\end{array}$ \\
\hline
\end{tabular}

From the analysis above, startups focus to be aware and are able to predict the mistakes. They believe that mistakes lead them to learn fast. Result of analysis diversity variable shows that the purpose of building network with different people variations will influence the propensity to innovate than the network density (number of people) themselves.

Table 5. Analysis for Diversity Variable

\begin{tabular}{|l|c|l|}
\hline \multicolumn{1}{|c|}{ Startup } & $\begin{array}{c}\text { Index } \\
\text { QD }\end{array}$ & \multicolumn{1}{|c|}{ Network Heterogeneity } \\
\hline Skleem & 4.0 & Knowing self-capability \\
\hline Sarang Jasa & 7.6 & Building a network \\
\hline Tanijoy & 7.6 & Absorb the knowledge and master in new fields \\
\hline Shipper & 10 & Learn about character and business \\
\hline
\end{tabular}

\section{Discussion of the findings}

From the measurement of innovation mindset with BII, it is found that innovation mindser index of Sarang Jasa is 5.7, Skleem is 6.5, Tanijoy is 7.4 and Shipper is 8.4. From the above picture, Shipper has the highest value of 10 for the failure (plan to fail), diversity and believe variables, while the lowest index for collaboration and trust occurs in the Sarang Jasa. 


\section{Trust}

Trust is examined from two aspects: internal and external aspects. Internal aspects are used to explore information about how a founder choose a co-founder partner, builds partnership to initiate startup, overcomes the resource difficulties experienced by startup and how open to sharing information. While the external aspect for trust variable explains how the informants see the competitor. Although only one startup actually claim that everyone can be trusted, but all the four disagree that everyone tends to lie to get desire benefits.

\section{Resilience}

Plan to fail is sometimes required to measure the individual's ability to face failure, it is a construct of resilience and entrepreneurial failure. plan to fail can also be interpreted fail fast, grow fast. the sooner the failure is found in the early of developing digital startup, the sooner the startup grows, as long as individual in the startup is able to perform the failure analysis, adapt and fix it again continuously. from the statement "at the beginning of development of this startup, I must encounter failure many times". Of all informants, only Skleem who stated disagree. But, everyone agreed that they will make a new digital startup if the startup that currently run will fail. Facing high risk is also part of the element of resilience. from quick respond statement. everyone agreed to invest $5 \%$ of their revenues for a business that is not yet clear on its success. From the question "What is the highest risk you have ever experienced during the startup developing?". Sarang Jasa has the most different answer. According to Sarang Jasa, choosing a team is the highest risk for a founder. The wrong team selection can be a toxic for other elements. According to Skleem, do not make unpredictable future as an obstacle to take high risk decisions. In contrast to Shipper, who said that the real high risk lies not in the decision making, but in the process that occurred, it was the real high risk.

\section{Believe}

Believe in this construct is a perception that comes to the mindset of a person that he is capable of changing the world. From the quick response table above, Sarang Jasa and Shipper confirmed that when both of them encounter problems, then both are confident that they will deal with it easily. This is different from Skleem and Tanijoy, although the four informants agree and believe that what they are building is capable for changing the world. Skleem has lowest belief index because of the type of B2B will have small impact to the community. According to skleem, the highest risk of build a startup is the initiate to build startup itself. Same statement was said by TaniJoy, which both of them have the lowest belief index.

\section{Perfection}

Perfectionist variable it tells that perfect is not good, but good enough is perfect. Perfectionist is also illustrated that someone needs to take a moment to do exploration. On average all informants agree that perfection cannot be realized, there is always an error. It is also accordance with qualitative statement that completing product on time with minimum requirement will be better that waiting for the product to be perfect.

\section{Diversity}

Diversity explains that individual's ability to adapt and communicate in an environment different from himself or herself. This variable is closely related to Collaboration. Diversity also explains how a person interacts with others he does not know, feels welcome, happy to listen and feel free to connects. All informants stated that it was important for them to spend time to meet people from different area with them. Skleem said that it needs to be done to gain new knowledge, seek inspiration, know the capabilities, and expand network. Sarang Jasa stated that at least 1 (one) month to meet people from different area with himself, while Tanijoy 
recommended to meet people with different are every week to get acquainted with one new person. According to Tanijoy, meeting people with different area expertise they have will facilitate to learn new fields in short time relatively.

\section{Collaboration}

Collaboration explains how founders collaborate with internal and external members. There are two types of collaboration shown in this variable, the collaboration that occurs between individuals and teams and on competitors and partners or called coopetition. Interestingly, all three informants agreed that they should collaborate with competitors except one, same with the question "do you have to compete with your competitors?". It can be said that only two informant agreed that they should collaborate with competitors but also compete with them.

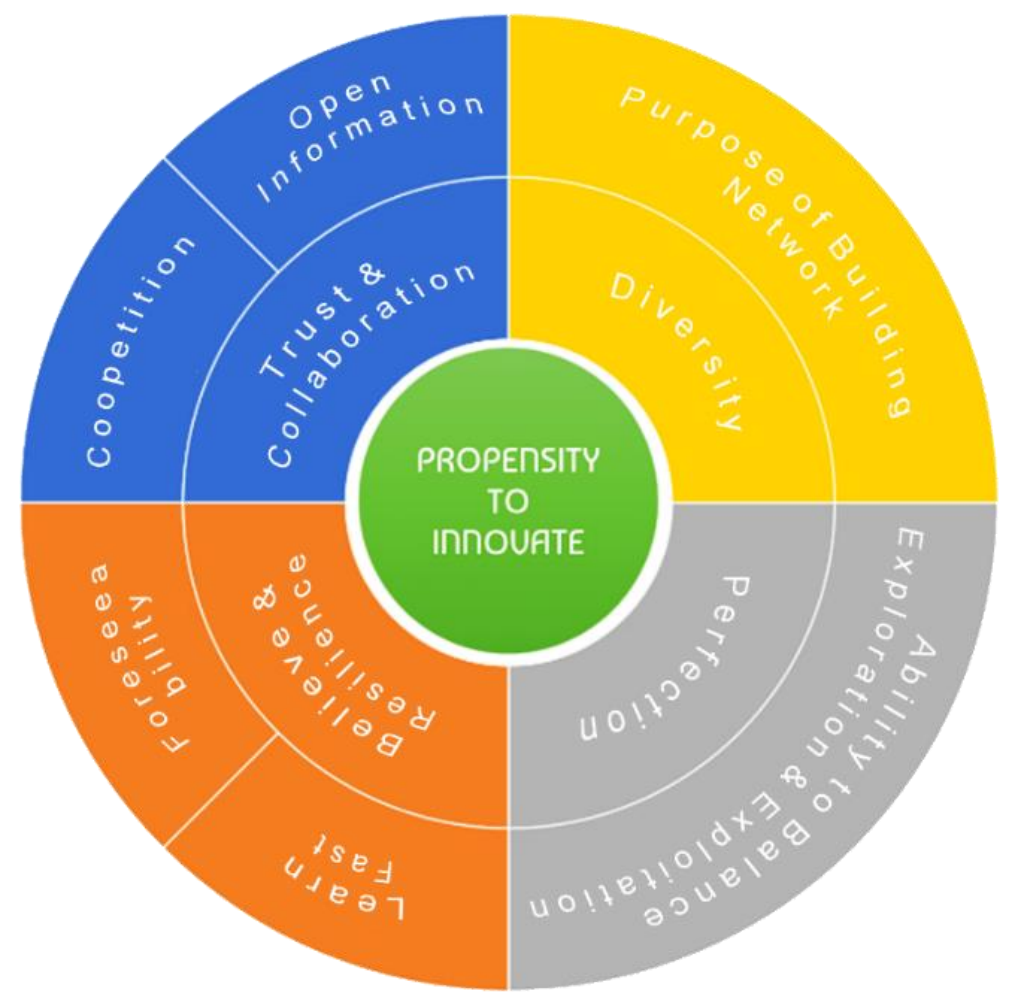

Figure 4: Personality Trait for Propensity to Innovate Model

\section{Conclusion}

Based on the results of research with qualitative methods using technique of observation, BII result, interviews and documents carried out. All informants have different perceptions on each variable of the BII index, by re-configuring based on BII it can be seen that the improvement of innovation can be done by these for propositions:

Proposition 1: Startups that share information openly and collaborate with the same startup area, but different products or expertise will have a propensity to higher innovate, compared to startups that share information only with mutual value assets and collaborate only with the startup who has same mission and vision. 
Proposition 2: Startups are aware and able to predict mistakes, then do not make the same mistakes lead to learn fast will have a propensity to higher innovate.

Preposition 3: Startups that divide their divisions to balance exploration and exploitation will have propensity to higher innovate that startups that do not divide the division for exploration and exploitation.

Proposition 4: The purpose of building networks with different people variations will influence the propensity to innovate than the network density (number of people) themselves. These proposition results then displayed in the Personality Traits for Propensity to Innovate Model.

\section{Acknowledgment}

This research was carried out in cooperation between Professor Ikhlaq Sidhu and Alexander Fredh-Ojala from Sutardja Center for Entrepreneurship and Technology at Berkeley, California.

\section{References}

Amore, M. D. (2015). Companies learning to innovate in recession. Research Policy, 44, 13741583.

Fontana, A. (2011). Innovate We Can! How to Create Value through Innovation in your Organization. Jakarta: Cipta Inovasi Sejahtera.

Giardino, C., Wang, X., \& Abrahamsson, P. (2014). Why early-stage software startups fail: A behavioral framework. International Conference of Software Business, Springer, Cham.

Hacioglu, G. (2012). The Effect of Entrepreneurial Marketing on Firms' Innovative Performance in Turkish SMEs. Procedia-Social and Behavioral Science 58, 871-878.

Hormiga, E., Hancock, C., \& Valls-Pascola, J. (2013). The Relationship between Employee Propensity to Innovate and Their Decision to Create a Company. Management Decision, 51(5), 938-953.

Kuczmarski, T. D. (1996). Fostering an Innovation Mindset. Journal of Consumer Marketing, 13(1996), 7-13. doi:http://dx.doi.org/10.1108/07363769610152563

Kuczmarski, T. D. (2003). What is Innovation? and Why aren't companies doing more of it? Journal of Consumer Marketing Vol 20 NO 6, 536-541.

Larsson, J. E., \& Ojala, A. F. (2016). Construction of the Berkeley Innovation Index: A HigherOrder Item Response Theory Model Approach . Lund: Lund University.

Lee, J. S., \& Hsieh, C. J. (2010). A Research in Relating Entrepreneurship. Marketing Capability, Innovative Capability and Sustainde Competitive Advantage . Journal of Business \& Economic Research 8.

Mantas, V., \& Soderquist, K. E. (2010). Open Innovation: Activating the Entrepreneurial Mindset. Academic Conference International Limited.

Mathisen, J.-E., \& Arnulf, J. K. (2013). Competing Mindsets in Entrepreneurship: The cost and doubt. The International Journal of Management Education, 11, 132-141.

Ma'toofi, A. R., \& Tajeddini, K. (2010). The Effect of Entrepreneurship Orientation on Learning Orientation and Innovation: A Study of Small-Sized Business Firm in Iran. International of Trade, Economics and Finanace 1(3).

McGuirk, H., Lenihan, H., \& Hart, M. (2014). Measuring the impact of innovative human capital on small firms' propensity to innovate. Research Policy. 
Sarooghi, H., Libaers, D., \& Burkemper, A. (2015). Examining the Relationship between Creativity and Innovation: A Meta-Analysis of Organizational, Cultural \& Environmental Factors. Journal of Business Ventures.

Sidhu, I., Goubet, J.-E., Webber, H., Fredh-Ojala, A., Johnsson, C., \& Pries, J. C. (2016). Berkeley Innovation Index*: An Approach for Measuring and Diagnosing Individuals' and Organizations' Innovation Capabilities. Sutardja Center for Entrepreneurship \& Technology Technical Report.

Talke, K., Salomo, S., \& Kock, A. (2011). Top Management Team Diversity and Strategic Innovation Orientation: The Relationship and Consequences for Innovativeness and Performance. Product Innovation Management, 28, 819-823.

wikipedia. (n.d.). SeniorManagement. Retrieved May 2018, from https://en.wikipedia.org/wiki/Senior_management 